\title{
Demographics and clinical and economic characteristics of patients receiving total hip arthroplasty with and without muscle atrophy/weakness
}

\author{
This article was published in the following Dove Press journal: \\ ClinicoEconomics and Outcomes Research \\ 24 June 2013 \\ Number of times this article has been viewed
}

Nin $\mathrm{Wu}^{\prime}$

Shih-Yin Chen'

Yuan-Chi Lee'

Yang Zhao ${ }^{2}$

'United BioSource Corporation, Lexington, MA, USA; ${ }^{2}$ Eli Lilly and Company, Indianapolis, IN, USA
Correspondence:Yang Zhao

Novartis Pharma, One Health Plaza, East Hanover, NJ 07936, USA

Tel +l 8627783662

Fax + I 973 781 2390

Email yang-3.zhao@novartis.com; yzhao00@hotmail.com

\begin{abstract}
This study analyzed administrative claims by a US population with commercial or Medicare supplemental insurance to compare demographics, comorbid medical conditions, and health care utilization and costs among patients undergoing total hip arthroplasty (THA) with and without muscle atrophy/weakness (MAW). Patients were classified into three cohorts: having MAW during the 12 months previous to THA (pre-MAW); having MAW during or over the 12 months after THA (post-MAW); or no MAW claim (no-MAW). In total, 19,607 Medicare and 23,127 commercially insured patients were examined. Controlling for cross-cohort differences, both pre-MAW and post-MAW commercial cohorts had significantly higher total costs (\$6,697 and $\$ 8,594$, in USD respectively) and higher risk of all-cause hospitalization (odds ratios, 1.66 and 1.57, respectively) than the no-MAW cohort (all $P<0.05$ ) during the 1-year follow-up. Similar trends were observed in the Medicare population.
\end{abstract}

Keywords: total hip arthroplasty, muscle atrophy/weakness, health care costs, health care utilization

\section{Introduction}

Total hip arthroplasty (THA) is one of the most commonly performed surgical procedures in the US, with an estimated 148,000 discharges among individuals aged 45-64 years and 168,000 aged above 65 years in $2010 .^{1}$ The most common reasons leading to THA are pain and decreased quality of life resulting from osteoarthritis. ${ }^{2-4}$ Utilization of THA is projected to grow by $174 \%$ between 2005 and 2030 and will continue to grow substantially in the future because of an aging population and the obesity epidemic. . $^{2,5}$

A previous study found that low muscle strength was common in patients with poor physical functioning after THA: $73 \%$ of the 78 THA patients who complained of poor functionality after THA had muscle weakness. ${ }^{7}$ Muscle atrophy/weakness (MAW) has been found to persist for up to 2 years after hip replacement. ${ }^{8}$ However, no study has examined whether patients with or without MAW have different demographic and clinical characteristics.

Although previous studies have used extensive real-world data to examine the utilization trend over time and outcomes among patients with THA, few have focused on the costs associated with THA., ${ }^{2,3,9-11}$ Only one study over the past 10 years reported the annual costs before and after total joint replacement surgery in a commercially insured population with osteoarthritis, but that study did not distinguish between knee 
and hip arthroplasty. ${ }^{12}$ No study to date has examined the associations between MAW and health care utilization and costs among patients with THA.

Using a large US claims database from 2005 to 2010, the present study compared the demographics, comorbid medical conditions, and health care costs and utilization among THR patients with and without MAW. Populations both younger than 65 years, and 65 years and older were included and were examined separately. Results from the present study, which uses the most recent data, may advance the understanding of the burden of THA and how MAW impacts health care costs and utilization.

\section{Methods}

The Truven Marketscan ${ }^{\circledR}$ Commercial and Medicare Supplemental Insurance Databases (Truven Health Analytics, Ann Arbor, MI, USA) were analyzed for this study. Over 30 million enrollees from the commercial database (commercial population) were covered by approximately 100 payers that include large employers, health plans, government organizations, and public organizations. About 3 million enrollees in the Medicare Supplemental databases (Medicare population) were 65 years and older with both Medicare coverage as well as employersponsored supplemental insurance. These databases contain claims across inpatient, outpatient, and prescription drug services, as well as enrollment status, health plan type, and demographic characteristics such as age, gender, and region of residence. Medical service claims contain details of health service encounters such as date and place of service, provider type, plan- and patient-paid amounts, and International Classification of Diseases, 9th Revision, Clinical Modification (ICD-9-CM) diagnoses and procedure codes. Pharmacy claims contain information on dispensed medications including the National Drug Code, dispensed date, quantity, days supplied, and plan- and patient-paid amounts. All records can be linked via unique and encrypted personal identifiers to provide a longitudinal view of the health care services received.

Only individuals who had an inpatient stay associated with THA (ICD-9-CM procedure code 81.51 or Current Procedural Terminology codes 27130 and 27132) between January 1, 2006 and September 30, 2009 were identified. The date of the first THA admission was denoted as the index date. Patients receiving a prior THA procedure from 1 year through 7 days before the index date were excluded; all patients included were aged 50 to 64 years for the commercial population and at least 65 years old for the Medicare population as of the index date. Finally, to assess the health care resource utilization and costs in the 1 year before and
1 year after the procedure, all included patients must have continuous coverage from the 12 months before the index date (the pre-index period) through the 12 months after the discharge date recorded on the index hospital stay (the postindex period). Because Medicare and commercial plans have different reimbursement procedures and payment rates, patients in the Commercial and Medicare databases were analyzed separately. Commercially insured individuals in the Truven MarketScan database include employees and their dependents who purchased insurance coverage from private health plans via their employers. Coverage and cost sharing (eg, deductibles and copay) vary from plan to plan. Medicare, regulated and funded by the US government, provides insurance coverage for aged (65 years old or older) and disabled persons. Studies have suggested that Medicare generally has a lower reimbursement rate than commercial plans for the same procedure or service. ${ }^{13,14}$ Because health care costs are the main study outcome, separate analyses on commercially insured and Medicare patients minimize the bias introduced by these different payment rates.

Within each population, each patient was further classified into three mutually exclusive cohorts: pre-MAW, post-MAW, and no-MAW. The pre-MAW cohort included patients with medical claims associated with MAW (ICD-9-CM codes 335.1x, 335.21, 359.xx, 728.2x, or 728.87; see detailed descriptions in the Supplementary materials) during the 12 months before the index hospitalization. The post-MAW cohort contained patients whose first MAW claim was dated during or within the 12 months after the index hospitalization. The no-MAW cohort included patients without any MAW claim over the entire study period. The cohorts were created based on the assumption that the pre-MAW cohort included individuals who had pre-existing MAW due to hip problems or other health conditions before receiving THA, and the post-MAW cohort included individuals who developed MAW after the THA.

Patient demographic characteristics included age, gender, region of residence, and type of insurance coverage. The proportion of patients with comorbid osteoarthritis, osteoporosis, and rheumatoid arthritis was estimated. The burden of chronic disease was approximated using an adapted Charlson comorbidity index (CCI), which creates a score based on the presence or absence of 23 chronic conditions identified from claims during the pre-index period. ${ }^{15}$

Characteristics of the index hospitalization were assessed including the length of stay, total cost, and the patients' discharge status (ie, discharge to a skilled nursing facility [SNF], home, inpatient rehabilitation facility, short-term 
hospital, other facility, and other alive status). Health care resource utilization incurred during the pre- and post-index periods was assessed, including the proportion of any use and frequency of hospital stays, physician office visits, outpatient hospital visits, and emergency department (ED) visits. Any use of SNF, inpatient rehabilitation facility, home health care, physical therapy, or occupational therapy over the post-index period was also compared across cohorts. Direct medical costs were estimated as the sum of health plan paid amount of all medical and pharmacy claims that dated during the pre- and post-index periods, and compared across MAW cohorts. Major cost components (ie, inpatient, outpatient, and pharmacy costs) were estimated and compared across MAW cohorts as well. All costs were adjusted to 2011 US dollars using the medical care component of the Consumer Price Index. ${ }^{16}$

Patient demographic characteristics, comorbidities, health care resource use, and costs were summarized and compared among pre-MAW, post-MAW, and no-MAW cohorts, with no-MAW as the reference group. Chi-squared tests were used to detect statistically significant differences between cohorts for categorical variables (eg, gender, region of residence, health plan type, comorbidities, discharge status of index stay, and proportion with resource use); Student's $t$-test were used to assess differences in age, and the Wilcoxon rank-sum tests were used for CCI scores, length of index hospital stay, number of medical encounters by settings (ie, hospitalizations, physician office visits, outpatient hospital visits, and ED visits), and associated health care costs incurred during the pre- and post-index periods.

Generalized linear regressions with log link and gamma distributions were performed to assess the association between MAW cohorts and health care costs during the 12-month post-index period controlling for patient age, gender, region of residence, comorbid medical conditions,

Table I Patient characteristics

\begin{tabular}{|c|c|c|c|c|c|c|}
\hline & \multicolumn{3}{|c|}{ Commercially insured patients $(\mathbf{N}=23,127)$} & \multicolumn{3}{|c|}{ Medicare beneficiaries $(N=19,607)$} \\
\hline & Pre-MAW & Post-MAW & No-MAW & Pre-MAW & Post-MAW & No-MAW \\
\hline $\mathrm{N}$ (\% of population) & $323(1.4)$ & $\mathrm{I}, \mathrm{I} 76(5.1)$ & $21,628(93.5)$ & $332(1.7)$ & $909(4.6)$ & $18,366(93.7)$ \\
\hline \multicolumn{7}{|l|}{ Demographics } \\
\hline Age in years: mean (SD) & $58.2(3.9)^{*}$ & $57.9(4.0)$ & $57.7(4.0)$ & $78.2(6.6)^{*}$ & $77.6(6.4)^{*}$ & $75.9(6.1)$ \\
\hline Female (\%) & $59.4^{*}$ & $55.5^{*}$ & 50.3 & $67.5^{*}$ & $65.7^{*}$ & 60.5 \\
\hline US region of residence (\%) & $*$ & $*$ & & & & \\
\hline Northeast & 3.1 & 7.2 & 10.9 & 8.1 & 8.4 & 10.7 \\
\hline Midwest & 31.9 & 29.2 & 31.2 & 41.9 & 41.4 & 39.6 \\
\hline South & 50.5 & 48.7 & 40.3 & 31.6 & 29.5 & 27.2 \\
\hline West & 14.6 & 14.5 & 17.1 & 17.5 & 20.1 & 21.7 \\
\hline Unknown & 0.0 & 0.4 & 0.6 & 0.9 & 0.7 & 0.8 \\
\hline Health plan type (\%) & & $*$ & & $*$ & $*$ & \\
\hline Preferred provider organization & 64.7 & 65.7 & 60.0 & 25.0 & 30.4 & 26.6 \\
\hline Comprehensive & 11.2 & 10.2 & 10.5 & 67.8 & 59.9 & 61.2 \\
\hline Health maintenance organization & 9.6 & 11.3 & 14.9 & 0.6 & 1.3 & 1.5 \\
\hline Other & 12.7 & 11.3 & 13.1 & 4.5 & 6.4 & 9.3 \\
\hline Missing & 1.9 & 1.5 & 1.5 & 2.1 & 2.1 & $\mathrm{I} .4$ \\
\hline \multicolumn{7}{|l|}{ Pre-index period comorbidities } \\
\hline Charlson score: mean (SD) & $5.5(4.6)^{*}$ & $4.3(3.9)^{*}$ & $3.9(3.7)$ & $7.0(4.4)^{*}$ & $5.8(4.0)^{*}$ & $5.1(3.8)$ \\
\hline Osteoarthritis (\%) & $89.8^{*}$ & 92.8 & 93.2 & $85.8^{*}$ & 89.4 & 89.8 \\
\hline Osteoporosis (\%) & $32.2^{*}$ & 21.9 & 19.6 & $29.8^{*}$ & 24.3 & 19.4 \\
\hline Rheumatoid arthritis (\%) & $7.7^{*}$ & 4.6 & 4.0 & 3.3 & $4.4^{*}$ & 3.2 \\
\hline \multicolumn{7}{|l|}{ Index hospitalization } \\
\hline Length of stay: mean (SD) & $3.9(3.3)^{*}$ & $3.8(3.5)^{*}$ & $3.5(2.0)$ & $4.5(4.6)^{*}$ & $4.2(3.4)^{*}$ & $3.8(2.9)$ \\
\hline \multirow[t]{2}{*}{ Inpatient stay cost: mean (SD) } & $\$ 29,915$ & $\$ 31,703 *$ & $\$ 29,840$ & $\$ 22,114$ & $\$ 22,382^{*}$ & $\$ 20,848$ \\
\hline & $(\$ 15,834)$ & $(\$ 18,519)$ & $(\$ 18,257)$ & $(\$ 2 I, 04 I)$ & $(\$ 24,058)$ & $(\$ 19,303)$ \\
\hline Discharge status (\%) & $*$ & $*$ & & $*$ & $*$ & \\
\hline Home & 72.1 & 75.7 & 81.5 & 42.8 & 41.1 & 60.3 \\
\hline Skilled nursing facility & 9.0 & 10.5 & 6.1 & 24.1 & 26.7 & 17.9 \\
\hline Inpatient rehabilitation facility & 4.3 & 4.6 & 2.4 & 6.9 & 7.5 & 5.7 \\
\hline Short-term hospital & 3.1 & 2.1 & 1.4 & 18.1 & 16.4 & 10.0 \\
\hline Other facility & 1.2 & 2.1 & 1.3 & 2.4 & 2.3 & 1.2 \\
\hline Other living accommodation & 10.2 & 4.9 & 7.3 & 5.7 & 5.9 & 4.9 \\
\hline
\end{tabular}

Note: $* P<0.05$ compared to the no-MAW cohort; all costs are in USD.

Abbreviations: N, number; MAW, muscle atrophy/weakness; SD, standard deviation. 
CCI score categories, pre-index period health care resource use (ie, any hospitalization, ED, or outpatient hospital visit), and the discharge status of the index hospitalization. The adjusted cost difference for pre-MAW and post-MAW cohorts as compared with the no-MAW cohort was estimated by computing the difference of predicted costs by holding the covariates constant while changing the values of MAW cohort variables. ${ }^{17}$ For costs with many zero values (at least $10 \%$ of the patients), two-part models were then performed to estimate the marginal effects of MAW on health care costs. A logistic regression model was first applied to estimate the probability of having nonzero health care costs. ${ }^{18}$ A generalized linear model was used in the second stage to estimate the health care costs among patients with nonzero costs. The estimated costs were calculated through multiplying the predicted probability generated from the logistic regression by the estimated conditional costs from the generalized linear model. The adjusted difference in health care costs of pre-MAW and post-MAW cohorts compared with the no-MAW cohort were calculated in the same way when costs were estimated via generalized linear regressions with $\log$ link and gamma distributions. The 2.5 and 97.5 percentile of the 1,000 estimated marginal difference estimates by bootstrapping the two-part model with 1,000 iterations were used to construct the $95 \%$ confidence interval (CI) for statistical significance. ${ }^{19}$

The association between MAW status and the probability of having any all-cause and a hip replacement/revisionrelated hospitalization in the post-index period was examined via logistic regression. Additional explanatory variables included age, gender, US region of residence, comorbidities, CCI score categories, preperiod resource use, and discharge status of the index hospitalization. The odds ratio (OR) and 95\% CI for each explanatory variable were reported. All analyses were conducted using $\mathrm{SAS}^{\circledR} 9.2$ (SAS Institute, Inc, Cary, NC, USA); $P$-values $<0.05$ were considered to be statistically significant.

\section{Results}

Nearly 57,000 commercially insured individuals received THA between January 1, 2006 and September 30, 2009 (Table 1); among them, more than half $(n=28,662)$ had at least 12-month continuous enrollment before and after the index hospitalization with THA and did not have claims for THA in 7 days to 1 year before the index hospitalization. Of the remaining patients, 23,127 were between 50 and 64 years old and were included in the commercially insured analytical sample. Of the 30,597 Medicare beneficiaries who had THA between January 1, 2006 and September 30,
2009, 19,820 had an at-least 12-month continuous enrollment before and after the index hospitalization with THA, and did not have claims for THA in 7 days to 1 year before the index hospitalization. Among them, 19,607 were 65 years or older at the time of the THA and were included in the Medicare analytical sample. Of the selected individuals, $1.4 \%$ of the commercial population had MAW diagnoses prior to THA (pre-MAW) and 5.1\% during or after their THA (post-MAW). Similar results were seen in the Medicare population, with $1.7 \%$ of individuals in the pre-MAW and $4.6 \%$ in the post-MAW cohorts, respectively. In both study populations, pre- and post-MAW patients were significantly more likely to be female and older (except for commercial post-MAW cohort) compared with patients in the no-MAW cohort. The majority of the commercial patients resided in the South, whereas the majority of the Medicare patients were in the Midwest region. More than half of the commercially insured patients were insured via preferred provider organizations, but most Medicare patients had comprehensive coverage. Approximately $90 \%$ of patients had osteoarthritis. The pre-MAW cohort in both the commercially insured and Medicare populations had a lower prevalence of osteoarthritis, but a higher prevalence of osteoporosis compared with the no-MAW cohort (all $P<0.05$ ). Patients in the pre- and post-MAW cohorts had significantly higher CCI scores and a longer length of stay during the THA index hospitalization than did the no-MAW cohort (all $P<0.05$ ) in both the commercial and Medicare populations. Total costs associated with the index hospitalization were higher in the post-MAW cohort than in the no-MAW cohort (both $P<0.05$ ), but they were similar between the pre-MAW and no-MAW cohorts in both populations. More than three-quarters of patients in the commercially insured population were discharged home, whereas close to two-thirds of the patients in the Medicare population were discharged home, followed in frequency by discharge to SNF and short-term hospitals.

Table 2 presents the health care utilization over the 12 month pre- and post-index periods in both the commercially insured and Medicare populations. In general, the pre-MAW and post-MAW cohorts had significantly higher health care resource utilization during the pre- and post-index periods than did the no-MAW cohort, including any hospital stay, total hospital days, any mean number of outpatient hospital visits, and the mean number of ED visits. Pre-MAW and post-MAW cohorts were also significantly more likely to use SNF, inpatient rehabilitation, home health, physical therapy, and occupational therapy during the postindex period than did the no-MAW cohort. Over $67 \%$ of the 
Table 2 Health care resource utilization over the 12-month pre- and post-index periods

\begin{tabular}{|c|c|c|c|c|c|c|}
\hline & \multicolumn{3}{|c|}{$\begin{array}{l}\text { Commercially insured patients } \\
(N=23,127)\end{array}$} & \multicolumn{3}{|c|}{$\begin{array}{l}\text { Medicare beneficiaries } \\
(\mathrm{N}=19,607)\end{array}$} \\
\hline & Pre-MAW & Post-MAW & No MAW & Pre-MAW & Post-MAW & No MAW \\
\hline \multicolumn{7}{|l|}{ Pre-index period } \\
\hline Hospital stay $(\%)$ & $33.4^{*}$ & $12.7^{*}$ & 10.5 & $45.5^{*}$ & $21.6^{*}$ & 17.9 \\
\hline Total hospital days (N): mean (SD) & $3.5(9.2)^{*}$ & $0.8(3.5)^{*}$ & $0.6(2.8)$ & $3.2(6.1)^{*}$ & I.3 $(5.8)^{*}$ & $0.8(3.0)$ \\
\hline Physician office visits (\%) & 99.7 & 99.6 & 99.6 & 99.7 & 99.3 & 98.8 \\
\hline Physician office visits (N): mean (SD) & $28.7(19.8)^{*}$ & $18.3(15.3)^{*}$ & $16.8(14.1)$ & $28.7(18.4)^{*}$ & $22.4(16.8)^{*}$ & $17.8(13.1)$ \\
\hline Outpatient hospital visits (\%) & $94.1^{*}$ & $89.6^{*}$ & 87.3 & $96.1^{*}$ & $92.0 *$ & 87.9 \\
\hline Outpatient hospital visits (N): mean (SD) & $10.1(14.6)^{*}$ & $4.9(6.9)^{*}$ & $4.4(5.8)$ & $9.0(10.7)^{*}$ & $6.7(9.2)^{*}$ & $4.9(6.7)$ \\
\hline Emergency department visits (\%) & $30.3^{*}$ & 19.7 & 18.3 & $36.5^{*}$ & $28.3^{*}$ & 19.9 \\
\hline Emergency department visits (N): mean (SD) & $0.5(I . I)^{*}$ & $0.4(1.2)$ & $0.3(1.0)$ & $0.9(2.1)^{*}$ & $0.5(1.2)^{*}$ & $0.3(1.0)$ \\
\hline \multicolumn{7}{|l|}{ Post-index period } \\
\hline Hospital stay $(\%)$ & $34.4^{*}$ & $29.1 *$ & 19.7 & $29.5^{*}$ & $34.7^{*}$ & 20.7 \\
\hline Total hospital days (N): mean (SD) & $3.4(13.2)^{*}$ & $2.5(8.8)^{*}$ & I.I (4.2) & $2.5(10.4)^{*}$ & $3.3(11.5)^{*}$ & $1.2(4.9)$ \\
\hline Physician office visits (\%) & 99.4 & 99.5 & 99.3 & 99.1 & 99.3 & 98.7 \\
\hline Office visits $(\mathrm{N})$ : mean $(\mathrm{SD})$ & $25 . I^{*}(20.4)$ & $23.2 *(18.3)$ & $18.4(15.7)$ & $27.5^{*}(19.8)$ & $27 . I^{*}(18.8)$ & $20.0(15.6)$ \\
\hline Outpatient hospital visits (\%) & $84.2^{*}$ & $82.7^{*}$ & 76.3 & $87.1^{*}$ & $87.4^{*}$ & 78.7 \\
\hline Outpatient hospital visits (N): mean (SD) & $8.4(12.1)^{*}$ & $7.5(10.9)^{*}$ & $5.4(8.0)$ & $7.8(16.8)^{*}$ & $8.6(12.4)^{*}$ & $5.1(8.1)$ \\
\hline Emergency department visits (\%) & 22.3 & $24.7^{*}$ & 19.3 & $32.8^{*}$ & $39.9 *$ & 23.6 \\
\hline Emergency department visits (N); mean (SD) & $0.4(1.2)$ & $0.5(1.3)^{*}$ & $0.3(0.9)$ & $0.9(3.2)^{*}$ & $0.9(1.8)^{*}$ & $0.4(1.0)$ \\
\hline Skilled nursing facility stay (\%) & $16.1^{*}$ & $18.0^{*}$ & 9.6 & $47.3^{*}$ & $53.3^{*}$ & 30.4 \\
\hline Inpatient rehabilitation stay (\%) & $6.5^{*}$ & $6.0 *$ & 3.0 & $2.1 *$ & $2.9 *$ & 1.0 \\
\hline Home health visit (\%) & $5.3^{*}$ & $4.9 *$ & 3.3 & $2.4^{*}$ & $2.0 *$ & 1.0 \\
\hline Physical therapy (\%) & 70.6 & $80.3^{*}$ & 67.0 & $42.2^{*}$ & $53.7^{*}$ & 36.9 \\
\hline Occupational therapy (\%) & $23.2^{*}$ & $22.2^{*}$ & 16.9 & $16.0^{*}$ & $21.5^{*}$ & 10.8 \\
\hline
\end{tabular}

Note: $* P<0.05$ compared to the no-MAW cohort.

Abbreviations: N, number; MAW, muscle atrophy/weakness; SD, standard deviation.

commercially-insured patients used physical therapy, $17 \%$ to $23 \%$ used occupational therapy, and $10 \%$ to $18 \%$ had a SNF stay over the 12-month post-index period. Among the Medicare patients, $30 \%$ to $53 \%$ had a SNF stay, $37 \%$ to $54 \%$ had a physical therapy visit, and $11 \%$ to $22 \%$ had used occupational therapy.

Among commercially insured patients, the pre-MAW $(\$ 35,022)$ and post-MAW $(\$ 15,011)$ cohorts had higher mean total costs than the no-MAW patients $(\$ 12,952$; both
$P<0.05)$ over the pre-index period, with over $50 \%$ of the costs resulting from outpatient services (Table 3). Total costs increased from the pre- to post-index period the most for the post-MAW cohort, followed by the no-MAW cohort, but remained similar for the pre-MAW cohort. During the post-index period, pre-MAW patients had the highest total costs $(\$ 33,847)$ followed by the post-MAW $(\$ 27,904)$ and no-MAW cohorts $(\$ 17,049)$. Similar trends were observed in the Medicare population.

Table 3 Unadjusted health care costs over the 12-month pre- and post-index periods

\begin{tabular}{|c|c|c|c|c|c|c|}
\hline & \multicolumn{3}{|c|}{ Commercially insured patients $(\mathrm{N}=23,127)$} & \multicolumn{3}{|c|}{ Medicare beneficiaries $(N=19,607)$} \\
\hline & Pre-MAW & Post-MAW & No-MAW & Pre-MAW & Post-MAW & No-MAW \\
\hline \multicolumn{7}{|l|}{ Pre-index period: mean (SD) } \\
\hline Cost of inpatient stays & $\$ 13,964 *(35,|4|)$ & $\$ 3,406 *(13,890)$ & $\$ 2,949(13,610)$ & $\$ 10,7 \mid 9 *(23,135)$ & $\$ 3,897 *(13,235)$ & $\$ 3,179(13,303)$ \\
\hline Cost of outpatient visits & $\$ 17,523 *(22,596)$ & $\$ 9,433 *(19,983)$ & $\$ 7,770(12,298)$ & $\$ 16,852 *(20,066)$ & $\$ 9,704 *(15,247)$ & $\$ 7,303(11,766)$ \\
\hline Pharmacy costs & $\$ 3,535(6,095)$ & $\$ 2,172 *(3,879)$ & $\$ 2,234(4,074)$ & $\$ 4,064 *(4,94 I)$ & $\$ 3,894 *(4,264)$ & $\$ 3,297(3,779)$ \\
\hline Total cost & $\$ 35,022 *(50,392)$ & $\$ 15,0 \mid I *(28,9 \mid 7)$ & $\$ 12,952(21,533)$ & $\$ 31,636 *(36,011)$ & $\$ 17,494 *(24,649)$ & $\$ 13,780(20,639)$ \\
\hline \multicolumn{7}{|c|}{ Post-index period: mean (SD) } \\
\hline Cost of inpatient stays & $\$ 16,726 *(44,849)$ & $\$ 13,178 *(34,989)$ & $\$ 6,635(21,033)$ & $\$ 8,233 *(30,84 I)$ & $\$ 9,096 *(24,082)$ & $\$ 4,700(16,98 \mid)$ \\
\hline Cost of outpatient visits & $\$ 13,230 *(19,026)$ & $\$ 12,466 *(23,046)$ & $\$ 8,067(12,506)$ & $\$ 17,075 *(22,490)$ & $\$ 18,698 *(22,558)$ & $\$ 9,182(2|, 9| 6)$ \\
\hline Pharmacy costs & $\$ 3,890(7,178)$ & $\$ 2,26 I^{*}(3,720)$ & $\$ 2,347(4,566)$ & $\$ 4,170 *(7,765)$ & $\$ 3,834 *(5,326)$ & $\$ 3,180(3,92 \mid)$ \\
\hline Total cost & $\$ 33,847 *(56,947)$ & $\$ 27,904 *(48,352)$ & $\$ 17,049(28,327)$ & $\$ 29,477 *(45,02 I)$ & $\$ 31,628 *(38,944)$ & $\$ 17,06 \mid(30,198)$ \\
\hline
\end{tabular}

Note: $* P<0.05$ compared to the no-MAW cohort; all costs are in USD.

Abbreviations: N, number; MAW, muscle atrophy/weakness; SD, standard deviation. 
After adjusting for patient demographic and clinical characteristics, commercial patients in both the pre- and post-MAW cohorts had significantly higher adjusted postindex total costs than those in the no-MAW cohort (adjusted cost difference: $\$ 6,697$ and $\$ 8,594$, respectively; both $P<0.05$ ) (Figure 1). Most of the total cost differences were

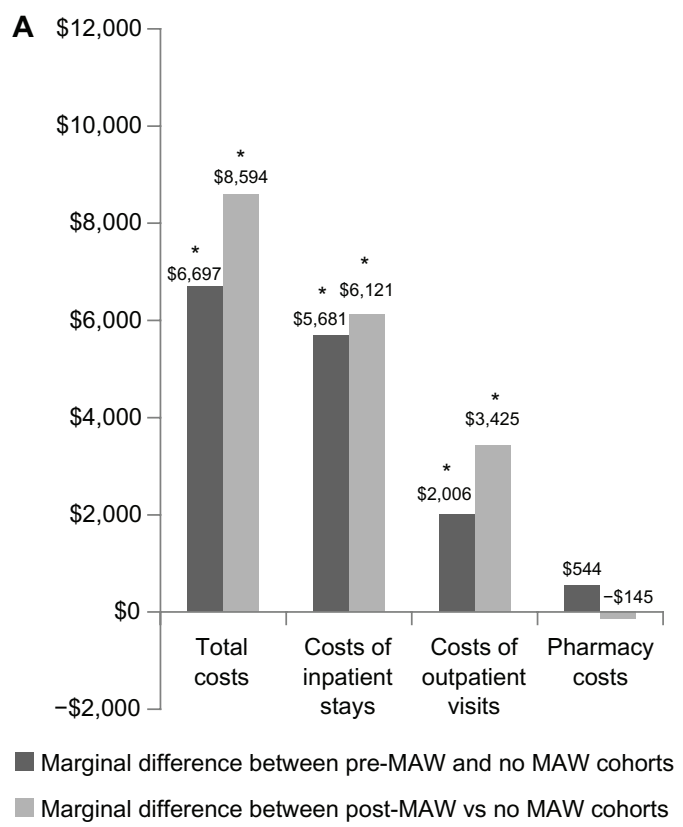

B

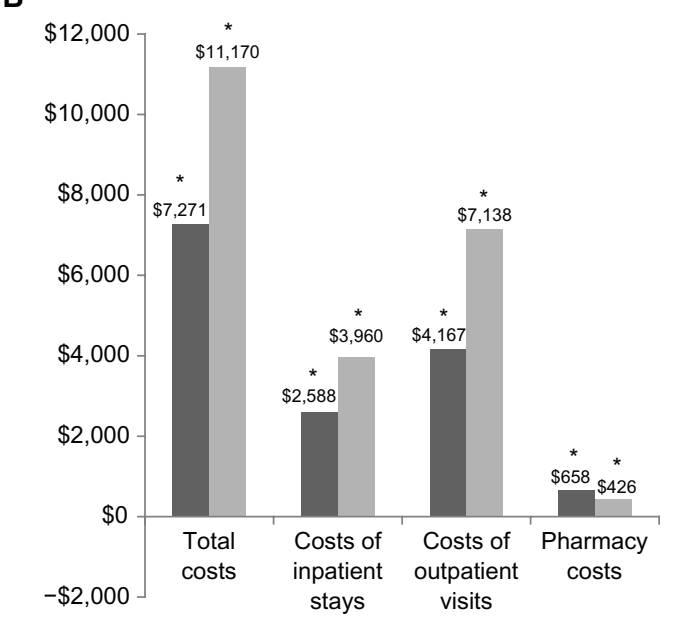

Marginal difference between pre-MAW and no MAW cohorts Marginal difference between post-MAW and no MAW cohorts

Figure I Marginal difference in health care costs over the 12-month post-index period.

Notes: (A) Commercially insured patients. (B) Medicare beneficiaries. $* P<0.05$ compared to the no-MAW cohort. Marginal differences for the total and outpatient costs were calculated by generalized linear regression models, adjusting for age, gender, US region of residence, health plan type, related comorbidities, discharge status of index hospitalization, and pre-index resource use. Inpatient and pharmacy costs were calculated by two-part models adjusting for age, gender, US region of residence, health plan type, related comorbidities, discharge status of index hospitalization, and pre-index resource use. All costs are in USD.

Abbreviation: MAW, muscle atrophy/weakness. attributed to the difference in inpatient costs $(\$ 5,681$ and $\$ 6,121$, respectively; both $P<0.05$ ), followed by outpatient costs $(\$ 2,006$ and $\$ 3,425$, respectively; both $P<0.05)$. Similarly, the pre- and post-MAW cohorts in the Medicare population had significantly higher total costs than the noMAW cohort (adjusted difference: $\$ 7,271$ and $\$ 11,170$, respectively; both $P<0.05$ ). However, most of this variation was due to the difference in outpatient costs $(\$ 4,167$ and $\$ 7,138$ respectively; both $P<0.05$ ).

Using logistic regression to control for cross-cohort differences in demographics, clinical, and economic characteristics, patients in the pre-MAW and post-MAW cohorts were more likely to have had a subsequent hospitalization during the 12-month post-index period than the no-MAW cohort (Table 4). Specifically, compared with no-MAW patients, commercially insured patients in the pre-MAW and post-MAW cohorts were 66\% (OR 1.66; $95 \%$ CI 1.31-2.11) and 57\% (OR 1.57; 95\% CI 1.38-1.80) more likely to have any hospitalization than those in the no-MAW cohort, respectively. A 28\% higher risk for the pre-MAW cohort (not statistically significant) and 90\% (statistically significant) for the post-MAW cohort were observed in the Medicare population. Other factors associated with a higher risk of any hospitalization include a higher CCI score $(>1)$, comorbid rheumatoid arthritis and osteoporosis, being discharged to SNF, and prior inpatient and ED use. When assessing hip replacement-related hospitalization, a higher risk was observed only for the pre-MAW (OR 1.76; 95\% CI 1:32-2.36) and post-MAW (OR 1.48; 95\% CI 1.25-1.75) cohorts in the commercially insured population.

\section{Discussion}

The number of total hip arthroplasties performed in the US has increased substantially in the past decade, and the number will continue to rise in the future. ${ }^{5}$ By year 2030, Kurtz et $\mathrm{al}^{5}$ have predicted that over a half million THAs will be performed during that year. The associated health care costs are also predicted to increase substantially. ${ }^{20}$ With the increased demand and costs associated with THA, it is important to understand the health care resource utilization and costs associated with THA and to identify subgroups of high-cost patients. To the best of our knowledge, this retrospective database study of both commercially insured and Medicare patients is the first to suggest that MAW is associated with higher health care utilization and costs among individuals who underwent THA. In particular, patients with MAW before receiving THA had the highest level of health care resource utilization and costs during the 
Table 4 Factors associated with hospitalization over the I2-month post-index period*

\begin{tabular}{|c|c|c|c|c|c|c|c|c|}
\hline & \multicolumn{4}{|c|}{ Commercially insured patients } & \multicolumn{4}{|c|}{ Medicare beneficiaries } \\
\hline & \multicolumn{2}{|c|}{$\begin{array}{l}\text { All-cause hospital } \\
\text { admissions }\end{array}$} & \multicolumn{2}{|c|}{$\begin{array}{l}\text { Replacement-related } \\
\text { hospital admissions }\end{array}$} & \multicolumn{2}{|c|}{$\begin{array}{l}\text { All-cause hospital } \\
\text { admissions }\end{array}$} & \multicolumn{2}{|c|}{$\begin{array}{l}\text { Replacement-related } \\
\text { hospital admissions }\end{array}$} \\
\hline & OR & $95 \% \mathrm{Cl}$ & OR & $95 \% \mathrm{CI}$ & OR & $95 \% \mathrm{Cl}$ & OR & $95 \% \mathrm{Cl}$ \\
\hline \multicolumn{9}{|l|}{ MAWa } \\
\hline Pre-MAW & 1.66 & $(1.31-2.11)$ & 1.76 & $(1.32-2.36)$ & 1.28 & $(1.00-1.63)$ & 1.38 & $(0.91-2.09)$ \\
\hline Post-MAW & 1.57 & $(1.38-1.80)$ & 1.48 & $(1.25-1.75)$ & 1.90 & $(1.64-2.19)$ & 1.22 & $(0.93-1.60)$ \\
\hline \multicolumn{9}{|l|}{ Charlson score ${ }^{b}$} \\
\hline 1 & 1.17 & $(1.03-1.32)$ & 1.01 & $(0.86-1.18)$ & 1.06 & $(0.91-1.22)$ & 0.99 & $(0.77-1.27)$ \\
\hline 2 or 3 & 1.47 & $(1.29-1.69)$ & 1.24 & $(1.04-1.47)$ & 1.25 & $(1.08-1.44)$ & 0.98 & $(0.76-1.27)$ \\
\hline $4+$ & 1.25 & $(1.15-1.35)$ & 1.04 & $(0.95-1.15)$ & 1.27 & $(1.15-1.39)$ & 1.18 & $(1.00-1.39)$ \\
\hline \multicolumn{9}{|l|}{ Selected comorbidities } \\
\hline Osteoarthritis & 0.95 & $(0.84-1.08)$ & 1.04 & $(0.88-1.24)$ & 0.98 & $(0.87-1.10)$ & 1.68 & $(1.31-2.17)$ \\
\hline Rheumatoid arthritis & 1.37 & $(1.18-1.59)$ & 1.22 & $(1.00-1.49)$ & 1.71 & $(1.44-2.03)$ & 1.32 & $(0.98-1.77)$ \\
\hline Osteoporosis & 1.13 & $(1.05-1.23)$ & 1.10 & $(0.99-1.22)$ & 1.13 & $(1.03-1.23)$ & 1.18 & $(1.02-1.37)$ \\
\hline \multicolumn{9}{|l|}{ Discharge status ${ }^{c}$} \\
\hline Skilled nursing facility & 1.34 & $(1.18-1.52)$ & 1.21 & $(1.03-1.43)$ & I.II & $(1.0 I-1.2 I)$ & 1.08 & $(0.92-1.26)$ \\
\hline Other facility & 1.39 & $(I .07-I .8 I)$ & 0.87 & $(0.58-1.31)$ & 0.86 & $(0.63-1.19)$ & 1.03 & $(0.59-1.78)$ \\
\hline Other living accommodation & 1.02 & $(0.89-1.16)$ & 0.89 & $(0.75-1.06)$ & 1.18 & $(1.01-1.38)$ & 1.07 & $(0.80-1.42)$ \\
\hline Inpatient rehabilitation facility & 2.04 & $(1.7 I-2.44)$ & 0.76 & $(0.56-1.02)$ & 1.13 & $(0.98-1.31)$ & 0.92 & $(0.70-1.22)$ \\
\hline \multicolumn{9}{|l|}{ Pre-index utilization } \\
\hline Hospitalization & 1.80 & $(1.64-1.98)$ & 1.40 & $(1.23-1.59)$ & 1.59 & $(1.46-1.73)$ & 1.04 & $(0.88-1.22)$ \\
\hline Outpatient hospital service & 1.18 & $(1.06-1.32)$ & 1.10 & $(0.95-1.26)$ & 1.05 & $(0.93-1.19)$ & 1.24 & $(1.00-1.54)$ \\
\hline Emergency department visit & 1.24 & $(1.14-1.34)$ & 1.02 & $(0.91-1.14)$ & 1.29 & $(1.18-1.40)$ & 1.04 & $(0.89-1.21)$ \\
\hline
\end{tabular}

Notes: ${ }^{a}$ Reference category: no-MAW; ${ }^{b}$ reference category, Charlson score $=0$; ' reference category, discharged home. ${ }^{*}$ Results from the logistic regressions were also adjusted for age, gender, US region of residence, and health plan type.

Abbreviations: $\mathrm{OR}$, odds ratio; $\mathrm{Cl}$, confidence interval; $\mathrm{MAW}$, muscle atrophy/weakness.

12 months before the procedure among the three cohorts, and patients who developed MAW during or after the THA had the most substantial increase of health care costs and the highest health care costs during the 12 months after THA.

Two studies have examined younger patients undergoing THA. ${ }^{10,12}$ However, one study is limited in terms of generalizability because it was conducted among veterans. The other study combined total knee and hip arthroplasty; therefore, it did not report results specifically for THA. The present study is, to the best of the authors' knowledge, the only study that uses the most recent data to provide patient characteristics, health care costs, and utilization for a patient population under 65 years of age undergoing THA. Consistent with findings from previous studies that examined THA in the Medicare population, the average age of the Medicare beneficiaries in the current study was mid-70s, and over $60 \%$ of patients were female. ${ }^{9,11}$ The length of hospital stay associated with THA was also similar to that in previous studies. The present study not only provided more detailed information on health care costs and utilization among Medicare patients after undergoing THA, but also confirmed that patients with MAW (before or after THA surgery) had higher health care resource use and costs than those without MAW. Therefore, health care providers may need to pay more attention to the high-cost subgroups when considering THA.

Patients in both the pre-MAW and post-MAW cohorts examined in this study were older and more likely to be female than those without MAW. As people age, muscle tends to be lost as part of the aging process. Studies also suggest that women are at a higher risk of developing MAW than men because women, in general, have less muscle mass and strength and lose muscle mass faster during menopause. ${ }^{21-23}$ Individuals undergoing THA who had MAW also had poorer overall health (as reflected by a higher average CCI score); this is consistent with existing clinical studies that suggest MAW often exists in individuals with disabling chronic conditions, such as chronic obstructive pulmonary disease, heart failure, and osteoporosis. ${ }^{24-30}$ Therefore, patients with overall poor health or many comorbidities may need to be further evaluated for MAW. Previous publications have found that MAW is reversible in many patients with timely and appropriate treatment as the development of MAW has been mainly attributed to long-term inactivity, biological changes resulting from aging or disease, and inadequate nutrition, and can be treated with a combination of appropriate exercise, nutrition, and pharmacological 
treatment. ${ }^{27,31-33}$ Treating MAW is especially important among patients receiving THA because MAW has been linked to impaired functional status, delayed rehabilitation, and increased risk of complications, such as joint instability and pain. ${ }^{7,8,34}$ Patients with MAW in the present study also had significantly higher health care utilization and costs than did those without MAW. Appropriate management of MAW among patients undergoing THA may lead to improved patient functioning, better quality of life, and potentially to cost savings.

There are several limitations to be considered when interpreting the results of this study. The identification of MAW was based on diagnostic codes in the medical claims and may be underreported in the administrative claims due to unrecorded diagnosis. That can lead to including misclassified patients in the no-MAW cohort. Such misclassification is likely to bias the estimate of health care costs associated with MAW. Emergency or elective hip arthroplasty were not differentiated in this study, because such information is absent in administrative claims data. Emergency care is generally associated with high costs. Because the proportion with elective surgery across the MAW cohorts is unknown, it is difficult to assess the impact of elective or emergency surgery on the study conclusions. No eligible patients included in the study received a prior hip arthroplasty in the previous 12 months, and all must have had at least 1 year of continuous enrollment before and after the index THA hospitalization. Therefore, findings derived from the current study may not be generalizable to other populations. Indirect costs and opportunity costs were not included in this study. It is also plausible that there were unobservable confounders that were not adjusted, which could result in biased estimates. Hence, findings from this analysis can be interpreted as associations instead of causations.

\section{Conclusion}

Among US patients undergoing THA, those with MAW had higher health care resource use and costs as compared to those without MAW. Commercially insured patients with MAW were also more likely to have any all-cause, as well as replacement-related, subsequent hospitalization than those without MAW.

\section{Acknowledgment}

Funding for this study was provided by Eli Lilly and Company.

\section{Disclosure}

Dr Zhao was employed by Eli Lilly and Company when this study was carried out. The authors report no other conflicts of interest in this work.

\section{References}

1. US Department of Health and Human Services: Centers for Disease Control and Prevention, National Center for Health Statistics. National Hospital Discharge Survey: 2010 table, procedures by selected patient characteristics - number by procedure, category and age. Available from: http://www.cdc.gov/nchs/data/nhds/4procedures/2010pro4_numberprocedureage.pdf. Accessed June 10, 2013.

2. Kurtz S, Mowat F, Ong K, Chan N, Lau E, Halpern M. Prevalence of primary and revision total hip and knee arthroplasty in the United States from 1990 through 2002. J Bone Joint Surg Am. 2005;87(7): 1487-1497.

3. Singh JA, Vessely MB, Harmsen WS, et al. A population-based study of trends in the use of total hip and total knee arthroplasty, 1969-2008. Mayo Clin Proc. 2010;85(10):898-904.

4. Montin L, Leino-Kilpi H, Suominen T, Lepistö J. A systematic review of empirical studies between 1966 and 2005 of patient outcomes of total hip arthroplasty and related factors. J Clin Nurs. 2008;17(1):40-45.

5. Kurtz S, Ong K, Lau E, Mowat F, Halpern M. Projections of primary and revision hip and knee arthroplasty in the United States from 2005 to 2030. J Bone Joint Surg Am. 2007;89(4):780-785.

6. Wilson NA, Schneller ES, Montgomery K, Bozic KJ. Hip and knee implants: current trends and policy considerations. Health Aff (Millwood). 2008;27(6):1587-1598.

7. Bhave A, Marker DR, Seyler TM, Ulrich SD, Plate JF, Mont MA. Functional problems and treatment solutions after total hip arthroplasty. J Arthroplasty. 2007;22(6 Suppl 2):116-124.

8. Rasch A, Byström AH, Dalén N, Martinez-Carranza N, Berg HE. Persisting muscle atrophy two years after replacement of the hip. J Bone Joint Surg Br. 2009;91(5):583-588.

9. Cram P, Lu X, Kaboli PJ, et al. Clinical characteristics and outcomes of Medicare patients undergoing total hip arthroplasty, 1991-2008. JAMA. 2011;305(15):1560-1567.

10. Singh JA, Sloan J. Higher comorbidity, poor functional status and higher health care utilization in veterans with prevalent total knee arthroplasty or total hip arthroplasty. Clin Rheumatol. 2009;28(9):1025-1033.

11. Vorhies JS, Wang Y, Herndon J, Maloney WJ, Huddleston JI. Readmission and length of stay after total hip arthroplasty in a national Medicare sample. J Arthroplasty. 2011;26(Suppl 6):119-123.

12. Bozic KJ, Stacey B, Berger A, Sadosky A, Oster G. Resource utilization and costs before and after total joint arthroplasty. BMC Health Serv Res. 2012;12:73.

13. Robinson JC. Variation in hospital costs, payments, and profitabilty for cardiac valve replacement surgery. Health Serv Res. 2011; 46 (6 pt 1):1928-1945.

14. Robinson J. Hospitals respond to Medicare payment shortfalls by both shifting costs and cutting them, based on market concentration. Health Aff (Millwood). 2011;30(7):1265-1271.

15. Charlson ME, Charlson RE, Peterson JC, Marinopoulos SS, Briggs WM, Hollenberg JP. The Charlson comorbidity index is adapted to predict costs of chronic disease in primary care patients. J Clin Epidemiol. 2008;61(12):1234-1240.

16. Bureau of Labor Statistics. Consumer Price Index [webpage on the Internet]. Washington, DC: Bureau of Labor Statistics. Available from: http://m.bls.gov/cpi/. Accessed June 14, 2012.

17. Basu A, Rathouz PJ. Estimating marginal and incremental effects on health outcomes using flexible link and variance function models. Biostatistics. 2005;6(1):93-109.

18. Diehr P, Yanez D, Ash A, Hornbrook M, Lin DY. Methods for analyzing health care utilization and costs. Ann Rev Public Health. 1999;20: $125-144$. 
19. Efron B, Tibshirani RJ. An Introduction to the Bootstrapping. New York, NY: Chapman and Hall; 1993.

20. Kurtz SM, Ong KL, Schmier J, et al. Future clinical and economic impact of revision total hip and knee arthroplasty. J Bone Joint Surg Am. 2007;89 Suppl 3:144-151.

21. Frontera WR, Hughes VA, Lutz KJ, Evans WJ. A cross-sectional study of muscle strength and mass in 45- to 78-yr-old men and women. JAppl Physiol. 1991;71(2):644-650.

22. Aloia JF, Vaswani A, Russo L, Sheehan M, Flaster E. The influence of menopause and hormonal replacement therapy on body cell mass and body fat mass. Am J Obstet Gynecol. 1995;172(3):896-900.

23. Phillips SK, Rook KM, Siddle NC, Bruce SA, Woledge RC. Muscle weakness in women occurs at an earlier age than in men, but strength is preserved by hormone replacement therapy. Clin Sci (London). 1993;84(1):95-98.

24. Harrington D, Anker SD, Chua TP, et al. Skeletal muscle function and its relation to exercise tolerance in chronic heart failure. $J \mathrm{Am}$ Coll Cardiol. 1997;30(7):1758-1764.

25. Vescovo G, Volterrani M, Zennaro R, et al. Apoptosis in the skeletal muscle of patients with heart failure: investigation of clinical and biochemical changes. Heart. 2000;84(4):431-437.

26. Bernard S, LeBlanc P, Whittom F, et al. Peripheral muscle weakness in patients with chronic obstructive pulmonary disease. Am J Resp Crit Care Med. 1998;158(2):629-634.
27. Franssen FM, Broekhuizen R, Janssen PP, Wouters EF, Schols AM. Limb muscle dysfunction in COPD: effects of muscle wasting and exercise training. Med Sci Sports Exerc. 2005;37(1):2-9.

28. HajGhanbari B, Hamarneh G, Changizi N, Ward AD, Reid WD MRI-based 3D shape analysis of thigh muscles patients with chronic obstructive pulmonary disease versus healthy adults. Acad Radiol. 2011;18(2):155-166.

29. Orsatti FL, Nahas EA, Nahas-Neto J, et al. Low appendicular muscle mass is correlated with femoral neck bone mineral density loss in postmenopausal women. BMC Musculoskelet Disord. 2011;12:225.

30. Di Monaco M, Vallero F, Di Monaco R, Tappero R. Prevalence of sarcopenia and its association with osteoporosis in 313 older women following a hip fracture. Arch Gerontol Geriatr. 2011;52(1):71-74.

31. Zak M, Swine C, Grodzicki T. Combined effects of functionallyoriented exercise regimens and nutritional supplementation on both the institutionalised and free-living frail elderly (double-blind, randomised clinical trial). BMC Public Health. 2009;9:39.

32. Fiatarone MA, Evans WJ. The etiology and reversibility of muscle dysfunction in the aged. J Gerontol. 1993;48 Spec No:77-83.

33. Wagner PD. Skeletal muscles in chronic obstructive pulmonary disease: deconditioning, or myopathy? Respirology. 2006;11(6):681-686.

34. Reardon K, Galea M, Dennett X, Choong P, Byrne E. Quadriceps muscle wasting persists 5 months after total hip arthroplasty for osteoarthritis of the hip: a pilot study. Intern Med J. 2001;31(1):7-14. 


\section{Supplementary material}

Table SI ICD-9 codes for muscle atrophy/weakness

\begin{tabular}{ll}
\hline Condition/ICD-9 code & Description \\
\hline $335.1 \mathrm{x}$ & Anterior horn cell disease; spinal muscular atrophy \\
335.21 & Anterior horn cell disease; motor neuron disease; progressive muscular atrophy \\
$359 . x x$ & Muscular dystrophies and other myopathies \\
$728.2 \mathrm{x}$ & Disorders of muscle, ligament, and fascia; muscular wasting and disuse atrophy, not elsewhere classified \\
728.87 & Disorders of muscle ligament and fascia; other disorders of muscle, ligament, and fascia; muscle weakness (generalized) \\
\hline
\end{tabular}

Abbreviation: ICD-9, International Classification of Diseases, ninth revision.

\section{Publish your work in this journal}

ClinicoEconomics \& Outcomes Research is an international, peerreviewed open-access journal focusing on Health Technology Assessment, Pharmacoeconomics and Outcomes Research in the areas of diagnosis, medical devices, and clinical, surgical and pharmacological intervention. The economic impact of health policy and health systems organization also constitute important areas of coverage. The manuscript management system is completely online and includes a very quick and fair peer-review system, which is all easy to use. Visit http://www.dovepress.com/testimonials.php to read real quotes from published authors

Submit your manuscript here: http://www.dovepress.com/clinicoeconomics-and-outcomes-research-journal 